\title{
Exploration and Practice of "Three-Track Integration" Teaching Method in Modern Enterprise Management Course
}

\author{
Chunguang Zhou, Huang Yan* \\ School of Economics and Management, Shihezi University, Shihezi 832000, Xinjiang, China.
}

Abstract: The influence of the thinking mode, there is certain limitation on the depth of the teaching content, in a certain lack of diversification of teaching methods, based on this, the research intends to explore the teaching mode under different management module, how to effectively solve the training goal, the linkage mechanism between theoretical knowledge and practical experience. In terms of teaching methods, this paper explores how the three-track teaching method of TBL-PBL-CBL can achieve the objectives of course teaching and talent cultivation by means of team cooperation, problem orientation and case discussion.

Keywords: Team Teaching; Case Teaching; Teaching Method

\section{Introduction}

The increasing demand of society for colleges and universities to cultivate comprehensive quality talents has promoted the reform and exploration of college teachers' teaching methods. Due to various reasons, the traditional teacher-centered teaching method has been unable to meet the requirements of modern educational teaching reform, which requires teachers to constantly explore new teaching methods. Especially for the discipline with strong comprehensiveness, practicality and application of management, how to combine theory with practice and theoretical knowledge with enterprise development? How to strengthen the students' professional theoretical accomplishment and at the same time, enrich, improve and cultivate students' practical ability?

At present, the reform of teaching methods mainly takes the form of the combination of online teaching and offline teaching with Internet technology as the medium and terminal technology means, flipped classroom and other teaching means. Although such methods of teaching reform to a certain extent, enriched the teaching methods, enhance the interactive teaching, improve the teaching. Based on this, this paper explores how the three-track teaching method of TBL-PBL-CBL can achieve the objectives of course teaching and talent cultivation by means of team cooperation, problem orientation and case discussion.

\section{The design of the three-track teaching method}

Michaelsen et al. (2008) formally proposed the TBL (team-based learning) teaching mode on the basis of studying many modern teaching modes. Based on team building and teamwork, this teaching mode prepares the teaching content and key points of the course, attaches importance to the learning process of solving problems and the specific application of knowledge, which is conducive to the efficient completion of teaching tasks. Problem-oriented and student-centered, PBL (problembased learning) teaching method converts course content into problems, advocates self-study combined with classroom discussion and cooperative problem-solving. With the rise of teaching mode reform, many new teaching methods emerge at the right moment. Among them, problem-oriented (PBL) teaching method and team-based learning (TBL) teaching method as representatives have been widely accepted by comprehensive and professional universities all over the world. CBL (case-based learning) teaching method is a case-based discussion teaching method.

Copyright(C) 2020 Chunguang Zhou et al.

doi: 10.18686/ahe.v4i10.2954

This is an open-access article distributed under the terms of the Creative Commons Attribution Non-Commercial License (http://creativecommons. org/licenses/by-nc/4.0/), which permits unrestricted non-commercial use, distribution, and reproduction in any medium, provided the original work is properly cited. 


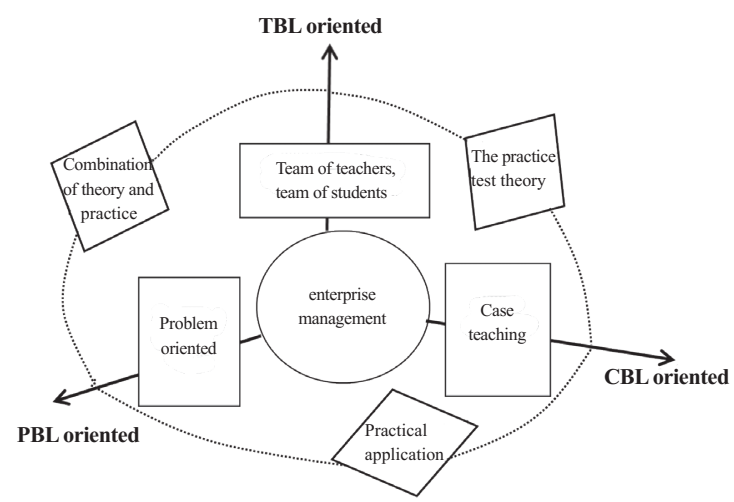

Figure 1. "three-track integration" teaching mode.

\subsection{TBL orientation}

TBL (Team-based learning) teaching model, on the basis of Shihezi University, institute of economics and management regulations, the construction of teaching organizations at the grass-roots level of the team building plan, in teaching and research section, curriculum group for the construction unit, in a professional and curriculum construction as the gripper, build team cooperation mechanism and promoting teaching "pass, side, belt", constantly improve the overall level of teachers' teaching ability. In the management of students, a learning mechanism with the school committee as the leader and the class committee as the core should be established to drive the course learning.

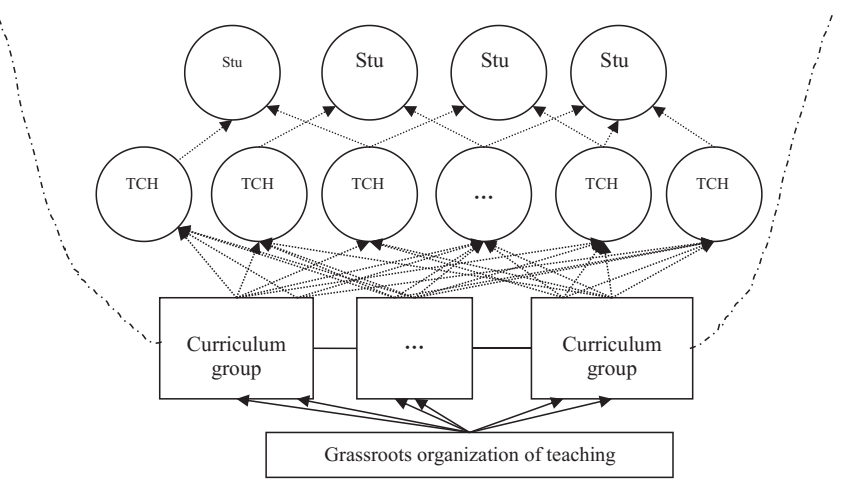

Figure 2. TBL guiding flow chart.

\subsection{PBL orientation}

Problem-oriented, student-centered, and with the development of social enterprises as a reference, PBL (problem-based learning) combines course content with practical problems in enterprise management, advocates self-learning by students combined with classroom discussion and cooperative problem-solving, and aims to cultivate students' independent learning ability and develop their comprehensive thinking ability. PBL orientation follows the "123" principle (Figure 3).

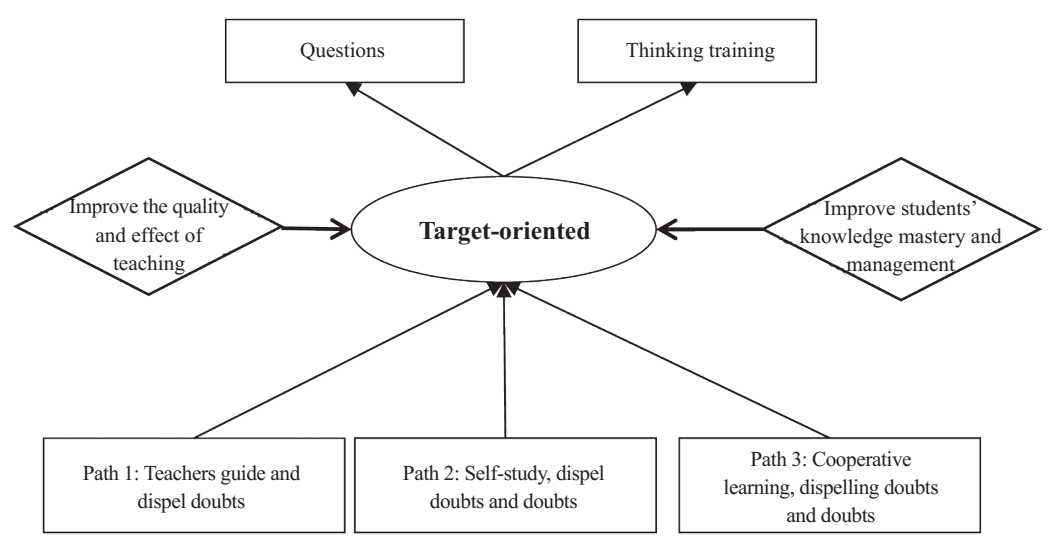

Figure 3. PBL guiding flow chart.

\subsection{CBL orientation}

CBL (case-based learning) teaching method is assisted by cases, combined with specific cases occurred in management 
practice, and based on different sections and knowledge points in course teaching, CBL (casebased learning) teaching method enables students to increase their ability to solve practical problems and enrich practical experience in enterprise management while choosing theories and explaining them. Case assisted teaching can be combined with practical teaching, such as case design competition and marketing survey competition. Practical knowledge of enterprise management can be enriched through the selection of specific cases, survey scheme design, questionnaire design, investigation process implementation, statistical data analysis, survey report writing and other links. As shown in Figure 4:

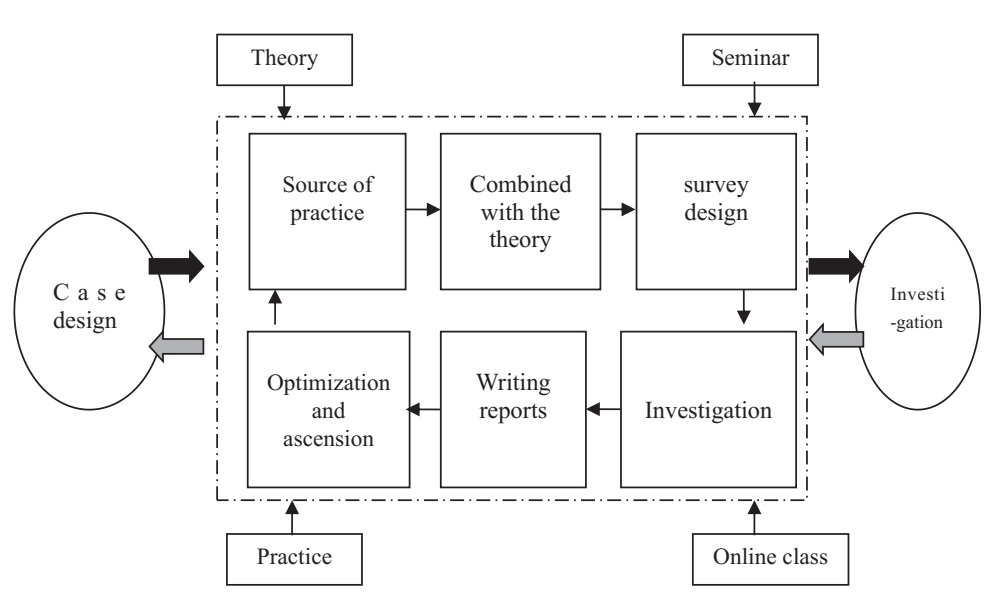

Figure 4. CBL guidance flow chart.

\section{The implementation of the three-track teaching method}

(1) Teaching (citing)_— The design of teaching resources and content. Traditional teaching is mainly teachers impart knowledge, such as teachers in the teaching of management in the process of case teaching is one of the commonly used method, analysis and interpretation, but they are mainly teachers and the teaching case from the students' cognitive, cannot cause the resonance of the students, therefore, to find and taught content knowledge fit high case, and to design the teaching content, through the interpretation of the case summary, analysis and discussion, guidance, deduce knowledge, will play a better effect.

(2) Learning (changing)—Students study independently. Through task-based learning, students are motivated to learn actively, such as consulting literature, reading management classics, searching for management cases in life, and analyzing students' self-management behaviors in combination with management knowledge points.

(3) Doing (understanding)—Students participate in practice, apply management knowledge, and have management experience and perception. Through the design content of the teaching practice, such as group to complete a task of cooperation, cooperation in research, so as to realize in cooperation to complete the task in the process of management activities.

\section{The safeguard measures of the three-track teaching method}

Firstly strengthen the construction of curriculum system and improve teaching methods and methods. In PDCA cycle, after several rounds of management course content system construction, to further enrich the course network resources, the establishment of three-dimensional teaching resource sharing platform. Plan to arrange the team teachers to the practice and training base or company research, improve the team teachers' practical teaching ability and level. Encourage team teachers to constantly improve teaching means and teaching design to ensure the quality of teaching.

Secondly, Pay attention to the relationship between curriculum construction and talent training. The goal of management specialty training is not only to meet the requirements of high-quality, practice-oriented and innovative research-based comprehensive talents of our college, but also to cultivate comprehensive talents with strong professional, practical and scientific research achievements. The purpose of modern enterprise management course construction is to cultivate students' comprehensive ability of paying attention to knowledge understanding and using knowledge to solve practical problems.

\section{References}

1. Michaelsen LK, Sweet M. Fundamental principles and practices of team based learning. Sterling (VA): Stylus Publishing 2008: 9-31.

2. Zhou C, Chen F, Wu Y. Application of task-driven case teaching in thematic curriculum teaching. Science and Technology 2019; (10): 23.

3. Juna, Liu Z. Practice and exploration of "TBL-PBL-CBL" three-track teaching method in enterprise management course. Think Tank Era 2019; (13): 206-207.

4. Zhou $\mathrm{C}$, Wu Y, Chen F. Interactive thematic curriculum education and teaching reform. Curriculum Education Research 2019; (13): 228 . 